\title{
Minor Axis Cross-sectional Diameter
}

National Cancer Institute

\section{Source}

National Cancer Institute. Minor Axis Cross-sectional Diameter. NCI Thesaurus. Code C135378.

The cross sectional diameter of a tissue, organ, or structure measured along its minor axis. 